\title{
Modification of Operational Characteristics of Cold Curing Silicon Rubber
}

\author{
V. V. Trachevskyi1,2, K. Yu. Ilina ${ }^{3}$, V. E. Yaremenko33, M. T. Kartel1,4, Bo Wang1 \\ ${ }^{1}$ Ningbo University of Technology, Ningbo, China \\ ${ }^{2}$ National Aviation University, Kyiv, Ukraine \\ ${ }^{3}$ Research and Production Association "Elastic", Kyiv, Ukraine \\ ${ }^{4} \mathrm{O}$. Chuiko Institute of Surface Chemistry, NASU, Kyiv, Ukraine \\ Email: meches49@ukr.net
}

How to cite this paper: Trachevskyi, V.V., Ilina, K.Yu., Yaremenko, V.E., Kartel, M.T. and Wang, B. (2019) Modification of Operational Characteristics of Cold Curing Silicon Rubber. Journal of Materials Science and Chemical Engineering, 7, 21-25. https://doi.org/10.4236/msce.2019.77003

Received: March 4, 2019

Accepted: July 7, 2019

Published: July 10, 2019

\begin{abstract}
Technological aspects of modifying the operational characteristics of cold cured silicate rubbers have been developed. The effect of chromium oxide on the resistance of cold-curing silicone compounds to thermal aging, as well as on the physic mechanical properties and dielectric characteristics has been studied. The various content of ultrafine chromium oxide in cold-cured silicone compositions has been investigated, it's optimal content in an amount of 2 - 5 mass at 100 mass, including low molecular weight rubber. Chromium oxide has been proven to improve the thermal stability of cold-cured silicone compositions. The manufacturing technology and component composition of the composition with high performance.
\end{abstract}

\section{Keywords}

Technological Aspects, Silicone Compounds, Cold-Curing, Modifying, Thermal Stability

\section{Introduction}

In the elements of aviation structures of large size and low rigidity rubber thermal protective coatings are used, which do not collapse when the structure is deformed. The use of rubber for supersonic aircraft and spacecraft is limited due to high requirements for heat and frost resistance of materials, as well as to their stability under the conditions of radiation and in a vacuum. Therefore, the development of new rubber with improved characteristics is an urgent problem [1] [2].

The development of modern technology contributes to the development of 
new materials with a specific set of useful properties. These include silicone elastomers, which have increased frost and heat resistance, good elasticity, high dielectric performance, atmospheric, moisture and ozone resistance, biological inertness. Along with hot-vulcanization silicone rubber based on high-molecular-weight silicone rubber, cold-curing compositions based on low-molecular-weight polyorganylsiloxanes are increasingly used. These compositions are now widely used in electronics, mechanical engineering, space and rocket technology, medicine, etc. [3].

Properties of rubber can be significantly modified by the introduction of fillers of different chemical nature, shape, size and specific surface area.

It is known that the use of ultrafine chromium oxide in hot-vulcanization silicone rubber increases their thermal-oxidative resistance [4] [5] [6].

Of considerable interest was the study of the effect of ultrafine chromium oxide as a heat stabilizing additive in cold-curing compositions, which are made on the basis of low molecular weight polymethylsiloxane rubber. The effect on the physic mechanical and dielectric parameters of silicone compositions has been studied.

\section{Experimental}

The objects of research were prototypes based on technical chromium, which is the ultrafine green powder with high hiding power, light, thermal and weather resistance.

As the basis of the studied compositions used serial low molecular weight synthetic polymethylsiloxane rubber filled with silica filler, which was introduced chromium oxide in the calculation of $1-10$ mas.\% at 100 mas.\% rubbers.

It was noted that with the introduction of chromium oxide in an amount of 10 mas.\% at 100 mas.\%, including rubber, within 3 - 5 days after the manufacture of the paste forms hardly mixed sediment.

As a control sample was taken silicone composition, not containing chromium oxide.

During the curing of the test samples, the organotin catalyst Penta-21P was used in an amount of 5 mass at 100 mass on the composition. This catalyst provides greater conventional strength and hardness of the silicone compositions, as well as a relatively fast course of the curing process at room temperature.

After curing, the silicone compositions were kept at a temperature of $20^{\circ} \mathrm{C}$ $25^{\circ} \mathrm{C}$ for 5 days until the properties were fully stabilized, after which tests were carried out according to physical and mechanical parameters on samples (I) with a thickness of $2 \mathrm{~mm}$, and resistance to thermal aging at a temperature of $250^{\circ} \mathrm{C}$ for $72 \mathrm{~h}$. The test results are shown in Table 1.

According to Table 1, diagrams were constructed for comparing physico-mechanical parameters under normal conditions and after thermal aging at a temperature of $250^{\circ} \mathrm{C}$ depending on the content of chromium oxide in the test samples, which are shown in Figures 1-3. 


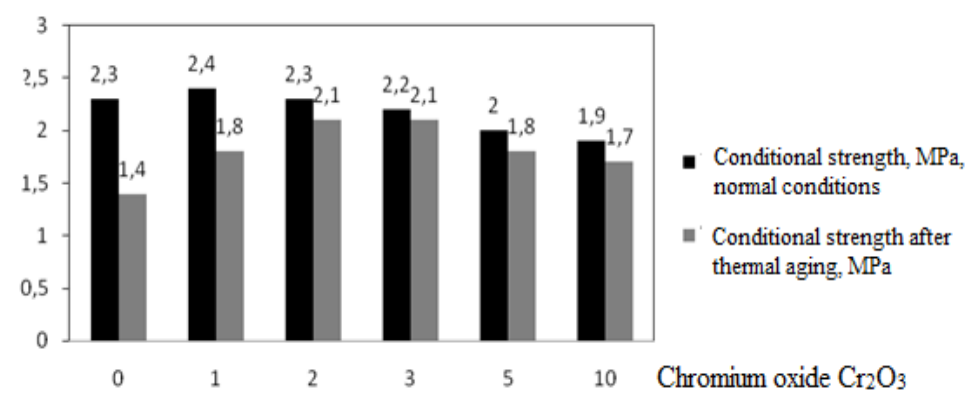

Figure 1. The change in the conditional strength of the investigated samples after thermal aging in the mode of $250^{\circ} \mathrm{C}$ for $72 \mathrm{~h}$ with different content of chromium oxide.

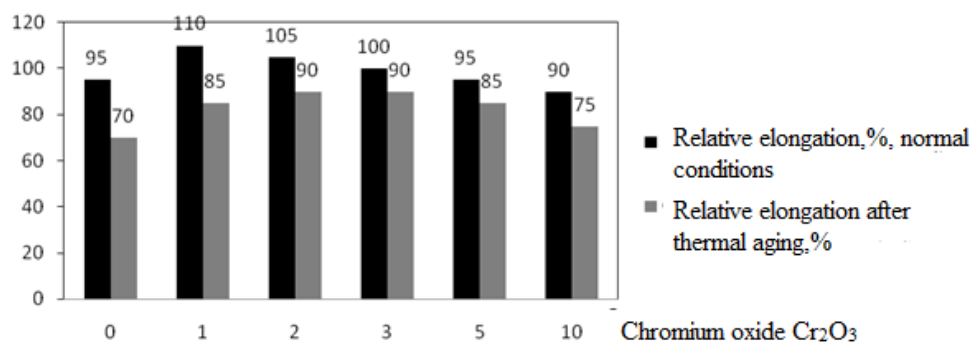

Figure 2. The change in the relative elongation of the samples after thermal aging in the mode of $250^{\circ} \mathrm{C}$ for $72 \mathrm{~h}$ with different content of chromium oxide.

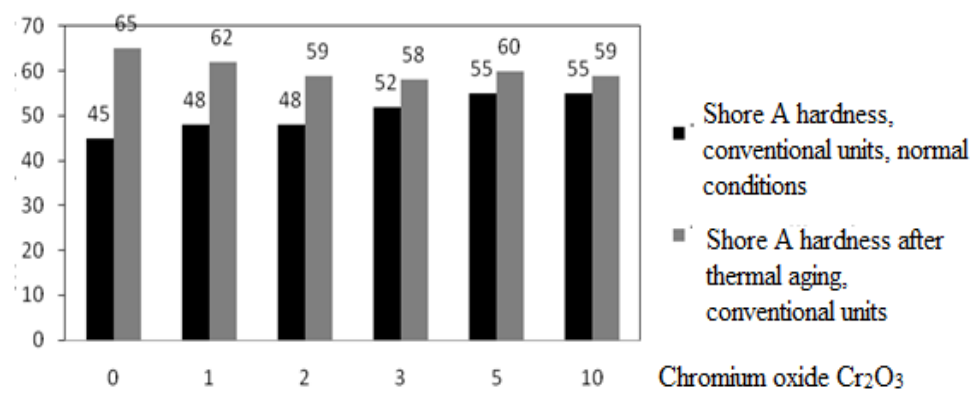

Figure 3. The change in hardness shore and the samples after thermal aging in the mode of $250^{\circ} \mathrm{C}$ for $72 \mathrm{~h}$ with different content of chromium oxide.

\section{Results and Discussion}

Analysis of the diagrams shows that, after thermal aging, the modified specimen's exhibit conditional strength and elongation at break, and their hardness is lower than that of the control sample, which does not contain chromium oxide. At the same time, under normal conditions, these indicators depend slightly on the content of chromium oxide.

Some decrease in conditional strength and relative elongation when the content of chromium oxide is more than 5 mas.\% at 100 mas.\% rubber is probably due to precipitation of the filler.

The dielectric properties of the studied samples were tested according to the following indicators: specific volume resistance and dielectric strength of silicone compositions.

The test results are shown in Table 2. 
Table 1. Recipe prototypes and the results of physico-mechanical tests.

\begin{tabular}{|c|c|c|c|c|c|c|}
\hline \multirow{2}{*}{ Denomination } & \multirow{2}{*}{$\begin{array}{l}\text { Control } \\
\text { sample }\end{array}$} & \multicolumn{5}{|c|}{ Samples } \\
\hline & & 1 & 2 & 3 & 4 & 5 \\
\hline Polymethylsiloxane rubber & 100 & 100 & 100 & 100 & 100 & 100 \\
\hline Silica filler & 25 & 25 & 25 & 25 & 25 & 25 \\
\hline Chromium oxide $\mathrm{Cr}_{2} \mathrm{O}_{3}$ & - & 1 & 2 & 3 & 5 & 10 \\
\hline PENTA-21P per 100 mass & 5 & 5 & 5 & 5 & 5 & 5 \\
\hline Cure time, $\mathrm{h}$ & 24 & 24 & 24 & 24 & 24 & 24 \\
\hline Conditional strength $\left(f_{0}\right), \mathrm{MPa}$ & 2.3 & 2.4 & 2.3 & 2.2 & 2.0 & 1.9 \\
\hline Relative extension $\left(\varepsilon_{0}\right), \%$ & 95 & 110 & 105 & 100 & 95 & 90 \\
\hline Shore A hardness $\left(H S h_{0}\right)$ & 45 & 48 & 48 & 52 & 55 & 55 \\
\hline \multicolumn{7}{|c|}{ After thermal aging after the regime $250^{\circ} \mathrm{C}$ and $72 \mathrm{~h}$} \\
\hline Conditional strength $\left(f_{1}\right), \mathrm{MPa}$ & 1.4 & 1.8 & 2.1 & 2.1 & 1.8 & 1.7 \\
\hline Changes $(\Delta f), \%$ & -39.1 & -25.0 & -8.7 & -4.5 & -10.0 & -10.5 \\
\hline Relative extension $\left(\varepsilon_{1}\right), \%$ & 70 & 85 & 90 & 90 & 85 & 75 \\
\hline Changes $(\Delta \varepsilon), \%$ & -26.3 & -22.7 & -14.3 & -10.0 & -10.5 & -16.7 \\
\hline Shore A hardness $\left(H S h_{1}\right)$ & 65 & 62 & 59 & 58 & 60 & 59 \\
\hline Changes ( $\triangle H S h), \%$ & +30.8 & +29.2 & +22.9 & +11.5 & +9.1 & +7.3 \\
\hline
\end{tabular}

Table 2. Dielectric test results.

\begin{tabular}{ccc}
\hline Type of composition & Specific volume resistance, $\mathrm{Ohm} \cdot \mathrm{cm}$ & Electric strength, $\mathrm{kV} / \mathrm{mm}$ \\
\hline Control sample & $2.41 \times 10^{14}$ & 16.52 \\
1 & $1.89 \times 10^{15}$ & 17.79 \\
2 & $4.05 \times 10^{15}$ & 19.77 \\
3 & $6.29 \times 10^{15}$ & 22.63 \\
4 & $7.15 \times 10^{15}$ & 20.81 \\
5 & $5.71 \times 10^{15}$ & 17.41 \\
\hline
\end{tabular}

\section{Conclusions}

According to the results of the whole complex of the conducted studies, it is clear that the optimal content of chromium oxide in the formulation of a silicone-silicone composition filled with silica filler is $2-5$ mas.\% at 100 mas.\%, including low molecular weight rubber.

It has been experimentally proved that chromium oxide improves the thermal stability of cold-cured silicone rubber vulcanized and improves their dielectric characteristics and can be used as a heat stabilizer.

At the same time, the optimal content of this heat stabilizer most likely depends on the specific formulation of the compositions and the type of the main filler, since at high doses it may provoke precipitation of a hardly mixing sludge. 
The research can be used in the development of new silicone compositions and cold-cured sealants.

\section{Conflicts of Interest}

The authors declare no conflict of interest.

\section{References}

[1] Kraev, I.D., Popkov, O.V., Sorokin, A.E. and Yurkov, G.Yu. (2017) Prospects for the Use of Silicone Polymers in the Creation of Modern Materials and Coatings for Various Purposes. Proceedings of VIAM, 12, 48-62. (In Russian)

https://doi.org/10.18577/2307-6046-2017-0-12-5-5

[2] Venediktova, M.A., Naumov, I.S., Chaikun, A.M. and Eliseev, O.A. (2014) Modern Trends in the Field of Fluorosiloxane and Siloxane Rubbers and Rubbers on Their Basis (Review). Aviation Materials and Technologies, S3, 17-24. (In Russian) https://doi.org/10.18577/2071-9140-2014-0-s3-17-24

[3] Zhang, D.S., Zeng, Z.Q. and Yu, H. (1992) Technical Improvements to Rubber Based on Low Temperature Vulcanization Silicone Rubber. China Synthetic Rubber Industry, 15, 184-189.

[4] Zhukovska, N.V., Rogova, S.V., Martsishin, R.L. and Vaskovsky, A.V. (2005) Metals Oxides. Effect on the Properties of Siloxane Rubber. Chemical Industry of Ukraine, 2, 50-53. (In Ukrainian)

[5] Andrianov, K.A. and Gridunov, I.G. (1998) Destruction of Siloxane Elastomers. Rubbers and Rubber, 11, 19-20. (In Russian)

[6] Nikitin, Yu.N., Manaeva, L.F. and Khodakova, S.Ya. (2004) On the Role of Combining Fillers in Strengthening Elastomers. Rubbers and Rubber, 4, 47-48. (In Russian) 